\title{
Weekly Cetuximab and Paclitaxel for Recurrent or Metastatic Head and Neck Squamous Cell Carcinoma
}

\author{
CHIHIRO FUSHIMI, DAISUKE BABA, TATSUO MASUBUCHI, MORIO YAMAZAKI, \\ YOSUKE KITANI, TATSUYA KITAJIMA, JUNPEI TANAKA, KENJI HANYU, \\ NARUHISA TANAKA, KOUKI MIURA and YUICHIRO TADA \\ Department of Head and Neck Oncology and Surgery, \\ International University of Health and Welfare Mita Hospital, Tokyo, Japan
}

\begin{abstract}
Background/Aim: Head and neck cancers account for $8 \%$ of all cancer cases worldwide. However, identifying the optimal treatment for recurrent or metastatic head and neck cancer (R/MHNSCC) has been challenging. The aim of this study was to evaluate the efficacy, safety, and prognostic factors of the outcome of patients with R/MHNSCC who were treated with weekly cetuximab and paclitaxel (Cmab-PTX). Patients and Methods: The records of R/MHNSCC patients who were treated with Cmab-PTX in our institution between June 2013 and September 2017 were collected. We analyzed Overall survival (OS), progression-free survival (PFS), prognostic factors and adverse events. Results: The records of 59 patients treated with Cmab-PTX were analyzed. The median PFS was 5.7 months, and the median OS was 11.8 months. Patients who had been administered cetuximab previously had shorter PFS and OS than those who had not. Conclusion: Cmab-PTX may be considered as a treatment option in head and neck R/MHNSCC patients.
\end{abstract}

Head and neck cancers account for $8 \%$ of all cancer cases worldwide; 1,450,000 new cases are diagnosed every year, and there are 500,000 related deaths annually (1). Identifying the optimal treatment for recurrent or metastatic head and neck squamous cell carcinoma (R/MHNSCC) has been challenging. However, treatment with immune checkpoint inhibitors (ICIs) in cases with high PD-L1 expression and biochemotherapy in other cases has recently gained attention (2). Increased treatment options contribute to a prolonged median overall

This article is freely accessible online.

Correspondence to: Yuichiro Tada, Department of Head and Neck Oncology and Surgery, International University of Health and Welfare Mita Hospital, 1-4-3 Mita, Minato-ku, Tokyo 108-8329, Japan. Tel: +81 334518121, Fax: +81 334540067, e-mail: ytada@iuhw.ac.jp

Key Words: Head and neck squamous cell carcinoma, paclitaxel, cetuximab, recurrent, metastasis. survival (OS) of R/MHNSCC ranging between 7.5-14.7 months (3). Therefore, not only the efficacy and safety of the treatment but also the choice of second- and later-line treatment plays an important role in oncologic outcomes.

The NCCN (National Comprehensive Cancer Network) guidelines recommend cetuximab ( $\mathrm{Cmab})$, cisplatin, and 5fluorouracil (5-FU) combination therapy (Extreme regimen) or pembrolizumab as first-line treatment (4-6). Recently, the combination of taxanes and $\mathrm{Cmab}$, for example, exchanging 5-FU for taxanes in the Extreme regimen, has drawn attention (7). Cmab and paclitaxel combination therapy (Cmab-PTX), first reported by Hitt et al. (8), is one such combination, and some studies have reported that $\mathrm{Cmab}-$ PTX has good efficacy for R/MHNSCC patients (7-16). However, the prognostic factors associated with Cmab-PTX have been inadequately reported $(9,10)$.

In this study, we retrospectively examined the efficacy and safety of Cmab-PTX in R/MHNSCC patients. We also assessed the predictors of outcomes in these patients.

\section{Patients and Methods}

Patients. This study was a retrospective analysis at a single institution. We reviewed the clinical records of patients with R/MHNSCC treated with Cmab-PTX between June 2013 and September 2017. The inclusion criteria were 18 years of age or older; at least one measurable lesion evaluated by computed tomography (CT) or magnetic resonance imaging (MRI); ECOG performance status (PS) of 2 or less and adequate hematologic, renal, and hepatic function; at least a 3-month life expectancy; and ability to provide written consent. Prior chemotherapy was allowed if administered as part of a multimodal treatment of head and neck squamous cell carcinoma. Exclusion criteria were pregnancy, drop-out before first evaluation for R/MHNSCC without disease progression or severe adverse events, and treatment with Cmab-PTX as maintenance therapy with the therapeutic effect of the Extreme regimen.

Written informed consent for the publication of this work was obtained from all patients. This study was approved by the institutional review board of the International University of Health and Welfare Mita Hospital (No. 5-19-66). 
Table I. Characteristics of the patients.

\begin{tabular}{lc}
\hline Number of patients & 59 \\
Age, years, median (range) & $66(58-75)$ \\
Male, $\mathrm{n}(\%)$ & $52(88)$ \\
Site of primary tumor, $\mathrm{n}(\%)$ & \\
Oral cavity & $21(36)$ \\
Hypopharynx & $17(29)$ \\
Oropharynx & $6(10)$ \\
Nasopharynx & $5(8)$ \\
Larynx & $4(7)$ \\
Maxillary sinus & $4(7)$ \\
Others & $2(4)$ \\
ECOG performance status, $\mathrm{n}(\%)$ & \\
0/1/2 & $46 / 12 / 1(78 / 20 / 2)$ \\
Type of recurrence, $\mathrm{n}(\%)$ & \\
Locoregional recurrence & $27(46)$ \\
Metastatic recurrence & $32(54)$ \\
Chemotherapy line & \\
$1^{\text {st }}$ & $35(59)$ \\
$2^{\text {nd }}$ & $19(32)$ \\
$3^{\text {rd }}$ or later & $5(8)$ \\
Previous chemotherapy, $\mathrm{n}(\%)$ & \\
Platinum & \\
Cetuximab & $41(70)$ \\
Docetaxel & $23(39)$ \\
Others & $23(39)$ \\
\end{tabular}

ECOG: Eastern Cooperative Oncology Group.

Treatment. Weekly Cmab was administered at an initial dose of 400 $\mathrm{mg} / \mathrm{m}^{2}$ and subsequently at doses of $250 \mathrm{mg} / \mathrm{m}^{2}$. Weekly PTX was administered at a dose of $80 \mathrm{mg} / \mathrm{m}^{2}$. All patients received dexamethasone before Cmab and H2-blocker before PTX. Treatment was continued until disease progression or unacceptable toxicity.

Dose reduction or delay was considered in the event of grade 3 non-hematologic adverse events or at the patient's request, and delay was considered in the event of grade 4 hematologic toxicity. Administration of PTX was reduced or delayed in the event of grade 3 hematologic toxicity.

Study design. The primary end point was OS. Secondary end points were overall response rate [ORR: complete response (CR)+partial response $(\mathrm{PR})]$, disease control rate [DCR: $\mathrm{CR}+\mathrm{PR}+$ stable disease (SD)], progression-free survival (PFS), duration of response, and safety. Additional end points were the prognostic factors affecting OS and PFS.

OS was defined as the period from the day of the initiation of treatment until the day of death, regardless of the cause. PFS was defined as the period from the day of the initiation of treatment to the day of disease progression or death. Duration of response was defined as the period from the first response [SD, PR, or progressive disease (PD)] until disease progression. Tumor response was assessed by CT or MRI before treatment and every 4 to 8 weeks until disease progression or treatment discontinuation according to the Response Evaluation Criteria in Solid Tumors, version 1.1. The evaluation of AEs was based on the Common Terminology Criteria for Adverse Events, version 4.0.

Statistical analysis. OS and PFS were estimated by the KaplanMeier method. Analysis of the relationship between age, sex, PS,
Table II. Efficacy of paclitaxel and cetuximab.

\begin{tabular}{lc}
\hline Number of patients & 59 \\
Best response, $\mathrm{n}(\%)$ & \\
$\mathrm{CR} / \mathrm{PR} / \mathrm{SD} / \mathrm{PD}$ & $8 / 19 / 16 / 16(14 / 32 / 27 / 27)$ \\
Overall response, $\mathrm{n}(\%)$ & $27(46)$ \\
Disease control, $\mathrm{n}(\%)$ & $43(73)$ \\
\hline
\end{tabular}

CR: Complete response; PR: partial response; $\mathrm{SD}$ : stable disease; PD: progressive disease.

existence of metastatic lesions, treatment line, and previous administration of platinum, Cmab, or docetaxel and OS or PFS were calculated using a univariate Cox regression model. All statistical analysis was carried out using EZR (Saitama Medical Center, Jichi Medical University, Saitama, Japan).

\section{Results}

Baseline clinical characteristics. Fifty-nine patients were eligible for inclusion. The median follow-up period was 16.3 months (95\% CI=8.5-30.0). Table I shows the baseline clinical characteristics of the patients. The mean age was 66 years old. Fifty-two patients were men (88\%). The most frequent primary site of the tumor was the oral cavity, followed by the hypopharynx and oropharynx. Most patients had a PS of 0 or 1. Thirty-two patients had metastatic recurrence with or without locoregional recurrence. $\mathrm{Cmab}+\mathrm{PTX}$ was the first-line regimen for recurrent or metastatic lesions in 35 patients. Forty-nine patients had previously received cisplatin and 23 patients had previously received Cmab.

Efficacy. The efficacy of Cmab+PTX in this study is shown in Table II. The ORR was $46 \%(95 \% \mathrm{CI}=33-60)$, and the DCR was $73 \%(95 \% \mathrm{CI}=60-84)$. Figure $1 \mathrm{~A}$ and $1 \mathrm{~B}$ show the Kaplan-Meier plots for the PFS and OS, respectively. The median PFS was 5.7 months $(95 \% \mathrm{CI}=3.9-10.3)$, and the median OS was 11.8 months $(95 \% \mathrm{CI}=7.5-17.4)$.

Prognostic factors. Table III shows the results of the Cox regression analysis for prognostic factors for the efficacy of Cmab-PTX. Patients who had previously received Cmab had significantly shorter PFS and OS than those who had not (PFS: $\mathrm{HR}=2.1,95 \% \mathrm{CI}=1.1-4.0$; $\mathrm{OS}$ : $\mathrm{HR}=2.0,95 \% \mathrm{CI}=1.1-3.6)$. There were no differences in PFS or OS between patients receiving Cmab-PTX as second- or later-line chemotherapy and those receiving it as first-line chemotherapy (PFS: $H R=0.9$, $95 \% \mathrm{CI}=0.5-1.6$; OS: $\mathrm{HR}=0.9,95 \% \mathrm{CI}=0.5-1.7)$. There were also no differences in PFS or OS between patients with a PS of 1 or 2 and those with a PS of 0 (PFS: $\mathrm{HR}=1.4,95 \% \mathrm{CI}=0.7-$ 3.0 ; OS: $\mathrm{HR}=2.0,95 \% \mathrm{CI}=1.0-4.2$ ).

Adverse events. Table IV shows the grade 1 to 4 (G1 to G4) adverse events of this study. The most common G3 or G4 


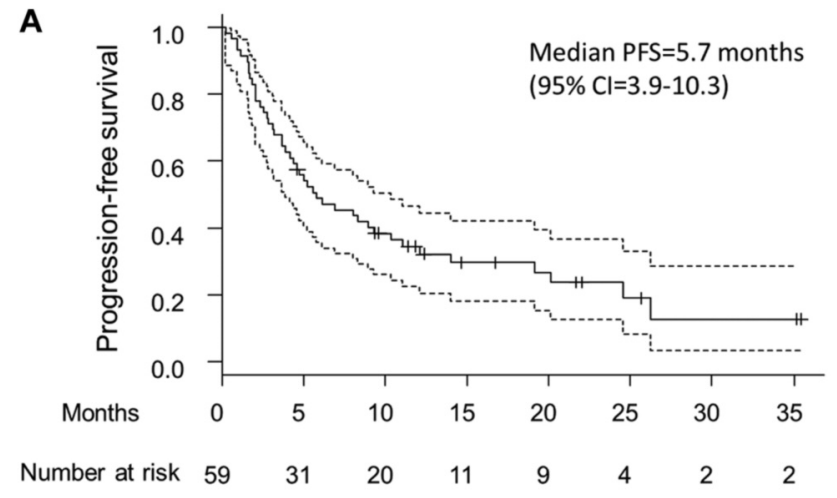

B

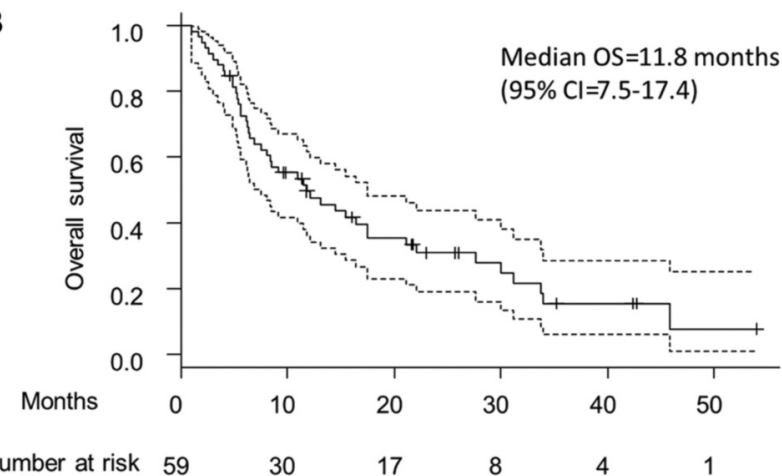

Figure 1. Sample collection and flow-chart of the study. A small number of cases were randomly selected as pilot studies and microarrays were performed. For saliva samples, the OSCC patient group (n=4) was compared with the HV group ( $n=4)$, and the expression levels of $m R N A$ were compared. The expression levels of mRNA in tissue samples were compared between the OSCC tissue group $(n=5)$ and the adjacent noncancerous tissues group $(n=5)$. In saliva, there were $207 m R N A s$ that demonstrated a $>2$-fold change in the OSCC patient group, compared to the HV group. In tissue, there were 3,041 mRNAs that demonstrated >2fold-change in the OSCC tissue group. Nine mRNAs that were upregulated more than 2-fold in both saliva and tissues were identified, and among these, NUS1 and RCN1 were selected for further investigation. HV: Healthy volunteers, OSCC: patients with oral squamous cell carcinoma.

adverse events were rash-acneiform $(\mathrm{n}=16,27 \%)$, anemia $(\mathrm{n}=10,17 \%)$, and neutropenia $(\mathrm{n}=9,15 \%)$. The most common G1 or G2 adverse event was anemia $(n=46,78 \%)$. Rashacneiform was observed in 31 patients. G1 or G2 peripheral neuropathies were observed in 26 patients, and there were no G3 or G4 peripheral neuropathy cases. Interstitial pneumonia was observed in two patients, one G2 and another G3. G1 or G2 infusion-related reactions were observed in two patients; no G3 or G4 infusion-related reactions were observed.

\section{Discussion}

This retrospective study of weekly Cmab-PTX for R/MHNSCC revealed an ORR of 44\%, a median PFS of 5.7
Table III. Univariate Cox Regression model for PFS or OS.

\begin{tabular}{|c|c|c|c|c|c|c|}
\hline \multirow[b]{2}{*}{ Variable } & \multicolumn{3}{|c|}{$\mathrm{PF}$} & \multicolumn{3}{|c|}{ OS } \\
\hline & HR & $95 \% \mathrm{CI}$ & $p$-Value & HR & $95 \% \mathrm{CI}$ & $p$-Value \\
\hline $\begin{array}{l}\text { Age }(>70 v s . \\
\leq 70)\end{array}$ & 1.0 & $0.5-1.9$ & $>0.99$ & 1.0 & $0.5-1.9$ & $>0.99$ \\
\hline $\begin{array}{l}\text { Gender (male } \\
v s . \text { female) }\end{array}$ & 1.8 & $0.8-4.1$ & 0.2 & 1.2 & $0.5-2.7$ & 0.7 \\
\hline $\begin{array}{l}\text { PS }(1 \text { or } 2 \\
v s .0)\end{array}$ & 1.4 & $0.7-3.0$ & 0.3 & 2.0 & $1.0-4.2$ & 0.06 \\
\hline $\begin{array}{l}\text { Metastatic } \\
\text { recurrence }\end{array}$ & 1.1 & $0.6-2.1$ & 0.7 & 1.1 & $0.6-1.9$ & 0.9 \\
\hline $\begin{array}{l}\text { Treatment line } \\
(\geq 2 \text { vs. } 1)\end{array}$ & 0.9 & $0.5-1.6$ & 0.7 & 0.9 & $0.5-1.7$ & 0.8 \\
\hline Previous CDDP & 0.9 & $0.5-1.8$ & 0.8 & 0.9 & $0.5-1.7$ & 0.8 \\
\hline $\begin{array}{l}\text { Previous } \\
\text { cetuximab }\end{array}$ & 2.1 & $1.1-4.0$ & 0.02 & 2.0 & $1.1-3.6$ & 0.03 \\
\hline Previous taxane & 1.0 & $0.5-1.8$ & $>0.99$ & 0.9 & $0.5-1.6$ & 0.7 \\
\hline
\end{tabular}

PFS: Progression-free survival; OS: overall survival; HR: hazard ratio; CI: confidence interval; PS: performance status; CDDP: cisdiamminedichloroplatinum.

Table IV. Common adverse events.

\begin{tabular}{lrrrr}
\hline & G1 & G2 & G3 & G4 \\
\hline Neutropenia & 6 & 6 & 8 & 1 \\
Febrile neutropenia & 0 & 0 & 1 & 0 \\
Thrombocytopenia & 7 & 2 & 1 & 0 \\
Anemia & 31 & 15 & 10 & 0 \\
Hyperkalemia & 22 & 4 & 5 & 0 \\
Hypokalemia & 10 & 4 & 2 & 0 \\
Hyperglycemia & 19 & 5 & 4 & 0 \\
Hypocalcemia & 6 & 5 & 2 & 0 \\
Increased CPK & 9 & 5 & 4 & 0 \\
Increased AST & 32 & 1 & 1 & 0 \\
Increased ALT & 25 & 2 & 0 & 0 \\
Increased ALP & 34 & 2 & 1 & 0 \\
Rash acneiform & 20 & 11 & 16 & 0 \\
Dry skin & 18 & 14 & 0 & 0 \\
Anorexia & 10 & 12 & 4 & 0 \\
Fatigue & 3 & 1 & 2 & 0 \\
Device-related infection & 0 & 0 & 4 & 0 \\
Mucositis & 10 & 0 & 2 & 0 \\
Interstitial pneumonia & 0 & 1 & 1 & 0 \\
Peripheral neuropathy & 13 & 3 & 0 & 0 \\
\hline
\end{tabular}

CPK: Creatine phosphokinase; AST: aspartate aminotransferase; ALT: alanine aminotransferase; ALP: alkaline phosphatase.

months, and a median OS of 11.8 months. Patients who had previously received Cmab had shorter PFS and OS than those who had not.

Hitt et al. (8) reported the first phase II study of CmabPTX in 2007. Other studies have reported ORRs of $30-55 \%$, 
median PFS of 3.9-7.7 months, and median OS of 7.6-16.8 months (8-16). The results of our study are consistent with those of previous studies. Conversely, Vermorken et al. (5) have reported the results of a phase III Extreme study of platinum-based chemotherapy and cetuximab in 2008, which had an ORR of $36 \%$, an OS of 10.1 months, and a PFS of 5.6 months. Additionally, Ferris et al. (6) have reported that the phase III Checkmate 141 trial of nivolumab in 2016 had an ORR of $13.3 \%$, an OS of 7.5 months, and a PFS of 2.0 months. Comparing the results of our study including second-line and later-line therapy with those of the Extreme study and CheckMate 141 trial, we suggest that weekly Cmab-PTX should be considered as a treatment option for R/MHNSCC, although we should take care when comparing retrospective studies to phase III clinical trials. Cmab-PTX might become one of the treatment options for patients who are refractory to platinum-based chemotherapy, have PD after receiving ICIs, or for whom ICIs are not suitable.

In subgroup analysis, we also examined the prognostic factors for the response to Cmab-PTX. Patients who had previously received $\mathrm{Cmab}$ had significantly poorer prognosis than those who had not. To our knowledge, this is the first study to report that previous administration of $\mathrm{Cmab}$ is a prognostic factor for survival in this cohort. The prognosis did not differ significantly between patients with a PS $\geq 1$ and those with a PS of 0 . This result is inconsistent with those of previous studies, which have shown that patients with a PS of 2 had significantly poorer prognosis than those with a PS of 0 or 1 (9). This might be because there were few patients with a PS of 2 in this study.

In our study, the most frequent G3 or G4 toxicities were rash $(27 \%)$, anemia (17\%), and neutropenia (15\%). Rash was more frequent in our study than in previous studies (11-13). This may be because there were more patients who had previously received regimens including Cmab in this study than in the previous studies. Thus, the total period of $\mathrm{Cmab}$ administration was longer. Anemia was also more frequent in our study than in previous studies (11-13). This may be because there were more patients who had previously received chemotherapy and more patients in poor condition. However, all adverse events were tolerable and manageable.

Our study had several limitations. Because this was not a phase III study, we cannot compare the efficacy of Cmab-PTX with that of other treatments. Further, this study was a singleinstitution retrospective series and we only examined the medical records to assess adverse events. Because of the small sample size, we could not perform multivariate Cox regression analysis. Therefore, our findings should be interpreted with caution.

\section{Conclusion}

In conclusion, our findings suggest that Cmab-PTX should be considered for the treatment of R/MHNSCC patients.
Patients who previously received Cmab might have poorer prognosis than those who did not. Further research is needed to confirm whether previous administration of $\mathrm{Cmab}$ is a predictor of poor response to Cmab-PTX.

\section{Conflicts of Interest}

The Authors declare that they have no competing interests related to this study.

\section{Authors' Contributions}

YT, DB and CF designed the study. DB, YT and CF contributed to the collection and interpretation of the data. CF, DB, TM, MY, YK, TK, JT, KH, NT, KM and YT contributed to data collection and patient management. $\mathrm{CF}$ was a major contributor in writing the manuscript. All Authors read and approved the final manuscript.

\section{Acknowledgements}

This work was supported by JSPS Grants-in-Aid for Scientific Research (C) to Dr. Yuichiro Tada (No. 18K09386). The Authors thank Editage (www.sditage.jp) for English language editing.

\section{References}

1 Bray F, Ferlay J, Soerjomataram I, Siegel RL, Torre LA and Jemal A: Global cancer statistics 2018: Globocan estimates of incidence and mortality worldwide for 36 cancers in 185 countries. CA Cancer J Clin 68(6): 394-424, 2018. PMID: 30207593. DOI: $10.3322 /$ caac.21492

2 Burtness B, Harrington KJ, Greil R, Soulières D, Tahara M, de Castro G, Jr., Psyrri A, Basté N, Neupane P, Bratland A, Fuereder T, Hughes BGM, Mesía R, Ngamphaiboon N, Rordorf T, Wan Ishak WZ, Hong RL, González Mendoza R, Roy A, Zhang Y, Gumuscu B, Cheng JD, Jin F and Rischin D: Pembrolizumab alone or with chemotherapy versus cetuximab with chemotherapy for recurrent or metastatic squamous cell carcinoma of the head and neck (keynote-048): A randomised, open-label, phase 3 study. Lancet 394(10212): 1915-1928, 2019. PMID: 31679945. DOI: 10.1016/S0140-6736(19)32591-7

3 Argiris A, Harrington KJ, Tahara M, Schulten J, Chomette P, Ferreira Castro A and Licitra L: Evidence-based treatment options in recurrent and/or metastatic squamous cell carcinoma of the head and neck. Front Oncol 7: 72, 2017. PMID: 5422557. DOI: $10.3389 /$ fonc.2017.00072

4 National Comprehensive Cancer Network: Head and neck cancer 2019; version 3, 2019. Available at: https://www.ncen.org/ professionals/physician_gls/ [Last accessed 20 May, 2020]

5 Vermorken JB, Mesia R, Rivera F, Remenar E, Kawecki A, Rottey S, Erfan J, Zabolotnyy D, Kienzer HR, Cupissol D, Peyrade F, Benasso M, Vynnychenko I, De Raucourt D, Bokemeyer C, Schueler A, Amellal N and Hitt R: Platinumbased chemotherapy plus cetuximab in head and neck cancer. N Engl J Med 359(11): 1116-1127, 2008. PMID: 18784101. DOI: 10.1056/NEJMoa0802656

6 Ferris RL, Blumenschein G, Jr., Fayette J, Guigay J, Colevas AD, Licitra L, Harrington K, Kasper S, Vokes EE, Even C, Worden F, 
Saba NF, Iglesias Docampo LC, Haddad R, Rordorf T, Kiyota N, Tahara M, Monga M, Lynch M, Geese WJ, Kopit J, Shaw JW and Gillison ML: Nivolumab for recurrent squamous-cell carcinoma of the head and neck. N Engl J Med 375(19): 18561867, 2016. PMID: 27718784. DOI: 10.1056/NEJMoa1602252

7 Guigay J, Tahara M, Licitra L, Keilholz U, Friesland S, Witzler $\mathrm{P}$ and Mesía R: The evolving role of taxanes in combination with cetuximab for the treatment of recurrent and/or metastatic squamous cell carcinoma of the head and neck: Evidence, advantages, and future directions. Front Oncol 9: 668, 2019. PMID: 31497530. DOI: 10.3389/fonc.2019.00668

8 Hitt R, Irigoyen A, Cortes-Funes H, Grau JJ, García-Sáenz JA and Cruz-Hernandez JJ: Phase ii study of the combination of cetuximab and weekly paclitaxel in the first-line treatment of patients with recurrent and/or metastatic squamous cell carcinoma of head and neck. Ann Oncol 23(4): 1016-1022, 2012. PMID: 21865152. DOI: $10.1093 / \mathrm{annonc} / \mathrm{mdr} 367$

9 Pellini Ferreira B, Redman M, Baker KK, Martins R, Eaton KD, Chow LQM, Baik CS, Goulart B, Lee SM, Santana-Davila R and Rodriguez CP: Predictors of outcome with cetuximab and paclitaxel for head and neck squamous cell carcinoma. Laryngoscope 127(7): 1583-1588, 2017. PMID: 27905113. DOI: 10.1002/lary.26422

10 Uozumi S, Enokida T, Suzuki S, Nishizawa A, Kamata H, Okano T, Fujisawa T, Ueda Y, Okano S, Tahara $\mathrm{M}$ and Yamaguchi M: Predictive value of cetuximab-induced skin toxicity in recurrent or metastatic squamous cell carcinoma of the head and neck. Front Oncol 8: 616, 2018. PMID: 30619755. DOI: 10.3389 /fonc. 2018.00616

11 Nakano K, Marshall S, Taira S, Sato Y, Tomomatsu J, Sasaki T, Shimbashi W, Fukushima H, Yonekawa H, Mitani H, Kawabata $\mathrm{K}$ and Takahashi S: A comparison of weekly paclitaxel and cetuximab with the extreme regimen in the treatment of recurrent/metastatic squamous cell head and neck carcinoma. Oral Oncol 73: 21-26, 2017. PMID: 28939072. DOI: 10.1016/ j.oraloncology.2017.07.022
12 Sosa AE, Grau JJ, Feliz L, Pereira V, Alcaraz D, Muñoz-García $\mathrm{C}$ and Caballero M: Outcome of patients treated with palliative weekly paclitaxel plus cetuximab in recurrent head and neck cancer after failure of platinum-based therapy. Eur Arch Otorhinolaryngol 271(2): 373-378, 2014. PMID: 23644939. DOI: $10.1007 / \mathrm{s} 00405-013-2537-6$

13 Jiménez B, Trigo JM, Pajares BI, Sáez MI, Quero C, Navarro V, Llácer C, Medina L, Rueda A and Alba E: Efficacy and safety of weekly paclitaxel combined with cetuximab in the treatment of pretreated recurrent/metastatic head and neck cancer patients. Oral Oncol 49(2): 182-185, 2013. PMID: 23026069. DOI: 10.1016/j.oraloncology.2012.09.003

14 Bernad IP, Trufero JM, Urquizu LC, Pazo Cid RA, de Miguel AC, Agustin MJ, Lanzuela M and Antón A: Activity of weekly paclitaxel-cetuximab chemotherapy in unselected patients with recurrent/metastatic head and neck squamous cell carcinoma: Prognostic factors. Clin Transl Oncol 19(6): 769-776, 2017. PMID: 28120324. DOI: 10.1007/s12094-016-1604-Z

15 Noronha V, Patil VM, Joshi A, Bhattacharjee A, Paul D, Dhumal S, Juvekar S, Arya S and Prabhash K: A tertiary care experience with paclitaxel and cetuximab as palliative chemotherapy in platinum sensitive and nonsensitive in head and neck cancers. South Asian J Cancer 6(1): 11-14, 2017. PMID: 28413788. DOI: 10.4103/2278-330x.202558

16 Péron J, Ceruse P, Lavergne E, Buiret G, Pham BN, Chabaud S, Favier B, Girodet D, Zrounba P, Ramade A and Fayette J: Paclitaxel and cetuximab combination efficiency after the failure of a platinum-based chemotherapy in recurrent/metastatic head and neck squamous cell carcinoma. Anticancer Drugs 23(9): 996-1001, 2012. PMID: 22643048. DOI: 10.1097/CAD.0b013e32835507e5

Received May 6, 2020

Revised May 19, 2020

Accepted May 20, 2020 